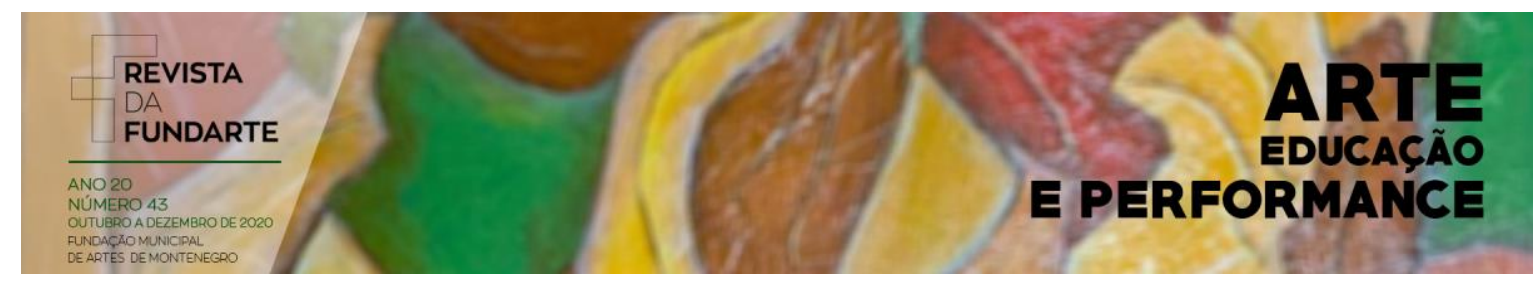

\title{
MEMÓRIAS DA DANÇA: ADEMIR PORTO CAVALHEIRO E OS PRIMÓRDIOS DA CULTURA HIP HOP EM PORTO ALEGRE
}

\author{
Anne Caroline Paz Ferreira \\ Flavia Pilla do Valle
}

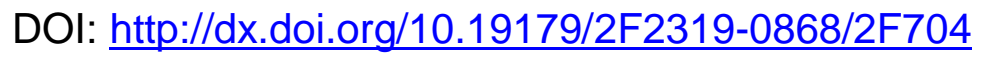

FERREIRA, Anne Caroline Paz; VALLE, Flavia Pilla. Memórias da dança: Ademir Porto Cavalheiro e os primórdios da cultura Hip Hop em Porto Alegre. Revista da FUNDARTE. Montenegro, p.01-20, ano 20, no 43, outubro/dezembro de 2020.

Disponível em: http://seer.fundarte.rs.gov.br/index.php/revistadafundarte/index> 20 de dezembro de 2020. 


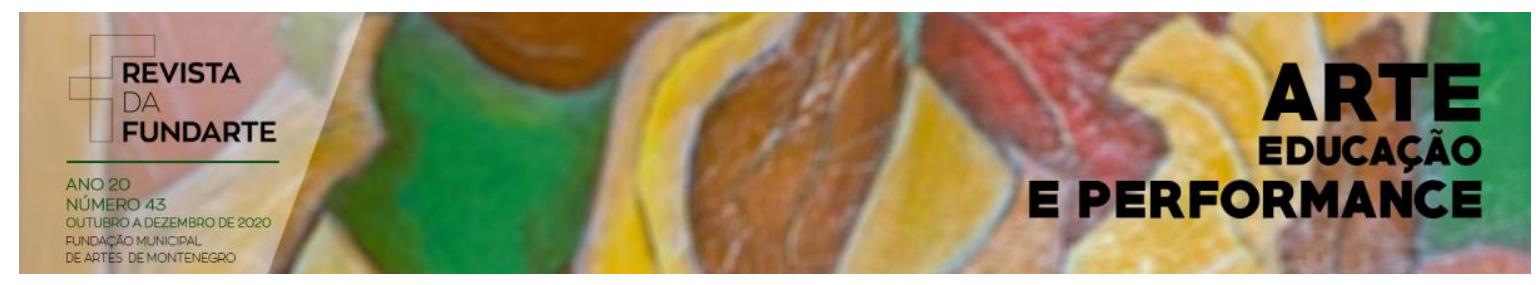

\title{
MEMÓRIAS DA DANÇA: ADEMIR PORTO CAVALHEIRO E OS PRIMÓRDIOS DA CULTURA HIP HOP EM PORTO ALEGRE
}

Anne Caroline Paz Ferreira ${ }^{1}$

Flavia Pilla do Valle ${ }^{2}$

\begin{abstract}
Resumo: Esta pesquisa busca investigar a história da dança no Rio Grande do Sul. Neste recorte, se quer saber sobre o universo das danças urbanas a partir da visão de um dos pioneiros do Hip Hop em Porto Alegre - Ademir Porto Cavalheiro (DJ Nezzo). Para investigar tais questões foi realizada uma entrevista que teve pauta semiestruturada com perguntas abertas. A partir disso, obteve-se dados sobre a cultura Hip Hop em relação aos primeiros contatos, grupos e eventos, relação com a tecnologia e representatividade negra. Pesquisar o Hip Hop é importante para gerar os registros históricos locais que, por sua vez, contribuem para fortalecer a identidade negra e fomentar uma educação que valorize as relações étnico-raciais.
\end{abstract}

Palavras-chave: História; Danças Urbanas; DJ Nezzo.

\section{DANCING MEMORIES: ADEMIR PORTO CAVALHEIRO AND THE HIP HOP CULTURE BEGGININGS IN PORTO ALEGRE}

\begin{abstract}
This research seeks to investigate the history of dance in Rio Grande do Sul. In this paper, it wants to know about the universe of urban dances from the vision of one of the pioneers of Hip Hop in Porto Alegre - Ademir Porto Cavalheiro (DJ Nezzo). To investigate such questions, an interview was conducted that had a semi-structured agenda with open questions. From this, data was obtained about Hip Hop culture in relation to the first contacts, groups and events, relation with technology and black representativeness. Researching Hip Hop is important in generating local historical records that, in turn, contribute to strengthening black identity and fostering education that values ethnic-racial relations.
\end{abstract}

Keywords: History; Urban Dances; DJ Nezzo.

\footnotetext{
${ }^{1}$ Licencianda em Dança pela UFRGS. Bolsista de Iniciação Científica desde 2017. Em 2018, recebeu o Prêmio Jovem Pesquisadora na área de Linguística, Letras e Artes no Salão UFRGS. É atuante na Cultura Hip Hop.

${ }^{2}$ Doutora em Educação pela UFRGS. Mestre em Dança pela New York University e Especialista pelo Laban/Bartenieff Institute, ambos reconhecidos pela UFBA. Tem experiência em dança contemporânea, moderna, balé e nas danças de vertente criativa. Faz parte do corpo docente da graduação em Dança (ESEFID) e da pós-graduação em Artes Cênicas (IA) da Universidade Federal do Rio Grande do Sul (UFRGS).
}

FERREIRA, Anne Caroline Paz; VALLE, Flavia Pilla. Memórias da dança: Ademir Porto Cavalheiro e os primórdios da cultura Hip Hop em Porto Alegre. Revista da FUNDARTE. Montenegro, p.01-20, ano 20, no 43, outubro/dezembro de 2020.

Disponível em: http://.seer.fundarte.rs.gov.br/index.php/revistadafundarte/index> 20 de dezembro de 2020. 


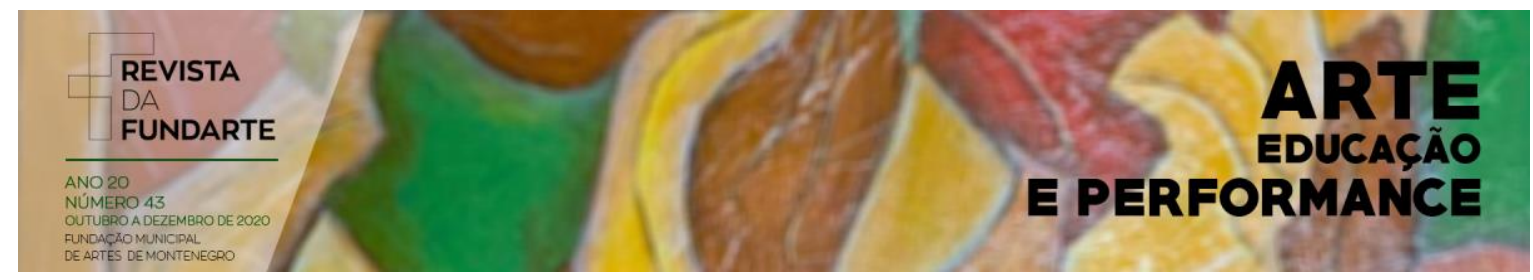

\section{Estabelecendo as Bases}

Esta pesquisa quer investigar a história da dança no Rio Grande do Sul como uma forma de memória da riqueza cultural que há nesse território. Sabe-se que a dança é uma cultura corporal que é eminentemente efêmera no seu fazer. Registrar essa arte, mesmo que de maneira escrita e não audiovisual, é, portanto, uma forma de preservação de uma cultura e de um conhecimento local. Neste recorte, analisase o universo das danças urbanas no Rio Grande do Sul a partir da visão de um dos pioneiros do Hip Hop em Porto Alegre, chamado Ademir Porto Cavalheiro ou, como é conhecido atualmente, DJ Nezzo.

O Hip Hop é uma manifestação artística relacionada à cultura de rua e às danças urbanas. A partir disso, algumas questões são levantadas: Como o movimento Hip Hop emergiu na cidade de Porto Alegre? Como aconteceu o intercâmbio de informações sobre essa cultura naquela época? Quem foram as pessoas ou grupos que iniciaram o fomento do Hip Hop na cidade? Quais foram os eventos que reuniram pessoas para a prática de dança?

Os praticantes atuais de Hip Hop aprendem muito sobre essa dança por meio da oralidade. Ao frequentar aulas e eventos dessa manifestação em Porto Alegre, frequentemente, se escuta sobre o DJ Nezzo e suas festas, assim como suas contribuições e importância como figura de referência para membros da cultura. Escrever sobre a história do DJ Nezzo, ou seja, escrever sobre Ademir Porto Cavalheiro é preservar uma história de uma cultura que ele ajudou a estabelecer e na qual inúmeros praticantes atuais estão tramados.

FERREIRA, Anne Caroline Paz; VALLE, Flavia Pilla. Memórias da dança: Ademir Porto Cavalheiro e os primórdios da cultura Hip Hop em Porto Alegre. Revista da FUNDARTE. Montenegro, p.01-20, ano 20, no 43, outubro/dezembro de 2020.

Disponível em: http://.seer.fundarte.rs.gov.br/index.php/revistadafundarte/index> 20 de dezembro de 2020. 

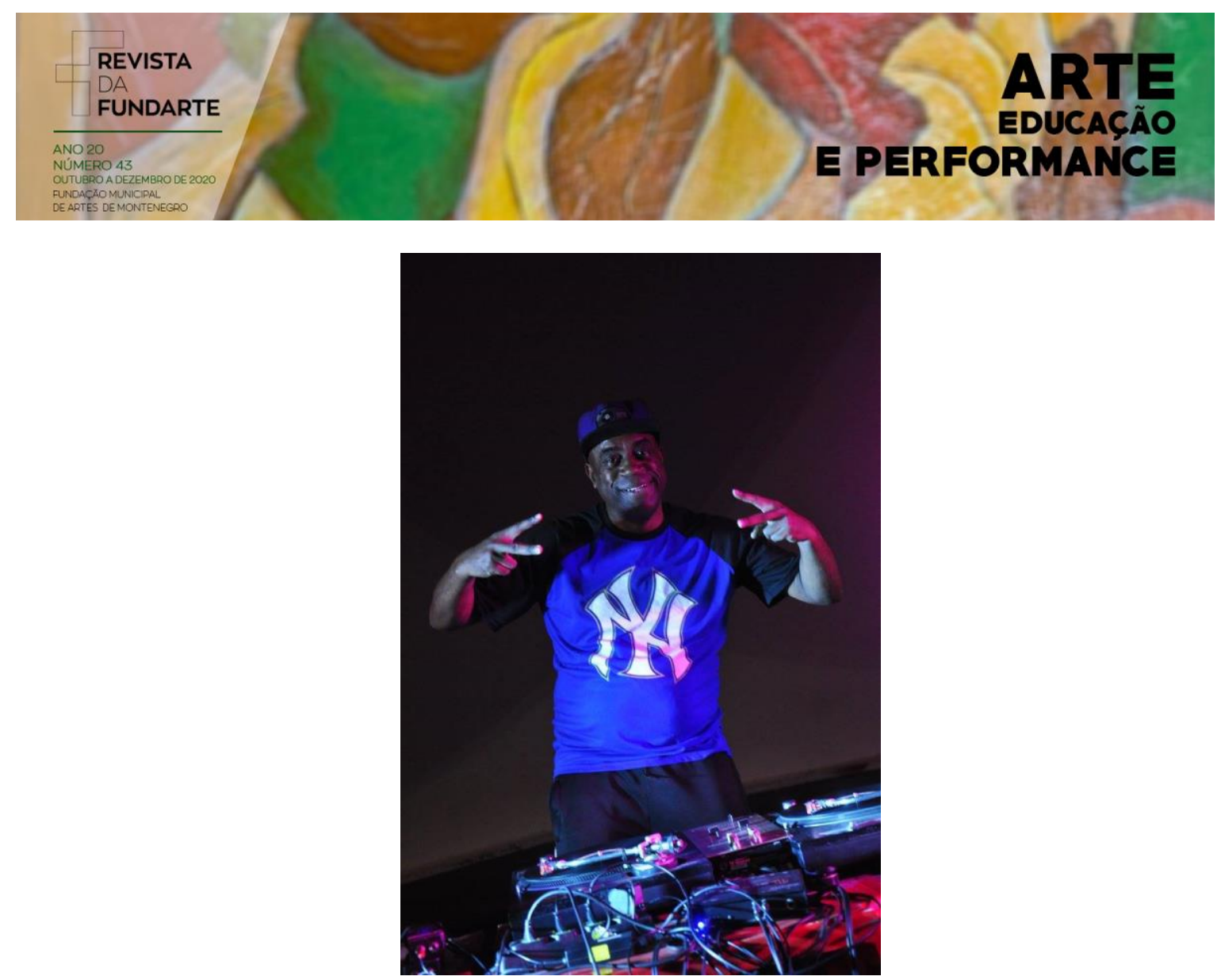

Figura 1: Ademir Porto Cavalheiro em 2018. Fonte: Acervo pessoal do entrevistado.

\section{Metodologia e Procedimentos}

Para investigar tais questões foi realizada uma entrevista de maneira presencial, que durou cerca de 45 minutos, no mês de agosto de 2018. Essa entrevista teve uma pauta semiestruturada com perguntas abertas, na qual preservou-se a fluidez da conversa e permitiu-se certas intervenções para o entendimento das informações fornecidas pelo entrevistado. Importante dizer que houve alguns contatos anteriores com o entrevistado, que já informalmente havia dado relatos sobre sua história de vida. Esses relatos contribuíram na elaboração das perguntas, e houve um cuidado por parte das entrevistadoras em registrar os relatos, antes informais, em dados da entrevista.

FERREIRA, Anne Caroline Paz; VALLE, Flavia Pilla. Memórias da dança: Ademir Porto Cavalheiro e os primórdios da cultura Hip Hop em Porto Alegre. Revista da FUNDARTE. Montenegro, p.01-20, ano 20, no 43, outubro/dezembro de 2020.

Disponível em: http://.seer.fundarte.rs.gov.br/index.php/revistadafundarte/index> 20 de dezembro de 2020. 


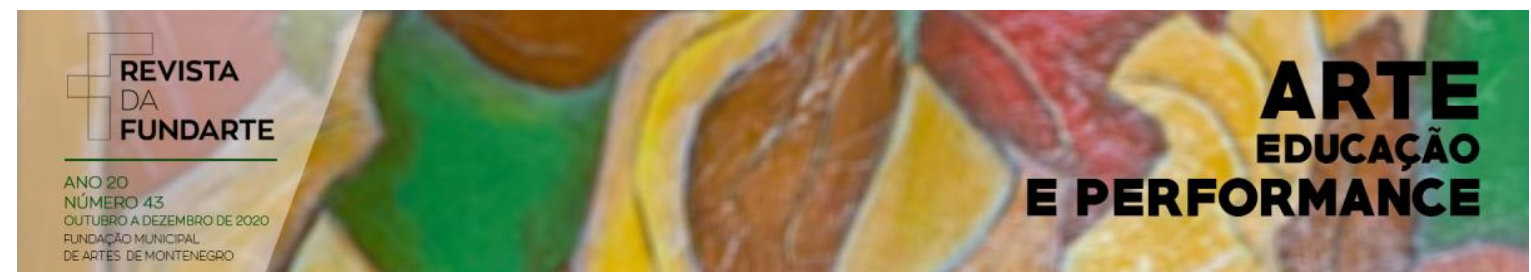

A entrevista foi gravada por meio de aparelho de áudio e, após a finalização, foram fornecidas pelo entrevistado algumas imagens, como fotografias e desenhos, algumas já digitalizadas nas redes sociais, e outras digitalizadas pelas autoras. As imagens fornecidas são, portanto, de domínio público, ou autorizadas pelo entrevistado. As autorizações se deram através de um Termo de Consentimento Livre e Esclarecido.

Visibilizar importantes membros da cultura da dança é dar luz à histórias, que se não forem registradas, se perderão com o tempo. Ademir é uma pessoa comum, mas que teve uma relevância no contexto do Hip Hop da cidade de Porto Alegre. A história da dança já é uma história que não é comumente contada em veículos oficiais. Porto Alegre, apesar de ser capital, não é um dos grandes centros culturais do País. Além disso, o Hip Hop como cultura de uma periferia negra era uma oposição à cultura europeia legitimada. A história de Ademir e a história do Hip Hop na cidade, corroboram com a ideia da história-vista-de-baixo, em que "[....] 0 movimento da história-vista-de-baixo também reflete uma nova determinação para considerar mais seriamente as opiniões das pessoas comuns sobre seu próprio passado, do que costumavam fazer os historiadores profissionais" (BURKE, 1992, p. 16).

\section{Sobre Ademir, a Tecnologia e a Cultura do Hip Hop}

Ademir Porto Cavalheiro é natural de Porto Alegre e nasceu em 1966. Atualmente trabalha como DJ, mas já foi praticante ativo da cultura do Hip Hop. Há quatro elementos na cultura Hip Hop: MC, DJ, Grafite, Break Dance. MC significa Mestre de Cerimônias, que é a pessoa que conduz o evento, ou faz a rima no RAP. DJ, ou Disc Jockey, representa o elemento da música e é a figura que faz as mixagens nos toca-discos. Grafite é o elemento visual da arte urbana, como pinturas os primórdios da cultura Hip Hop em Porto Alegre. Revista da FUNDARTE. Montenegro, p.01-20, ano 20, n -43 , outubro/dezembro de 2020.

Disponível em: http://.seer.fundarte.rs.gov.br/index.php/revistadafundarte/index> 20 de dezembro de 2020. 


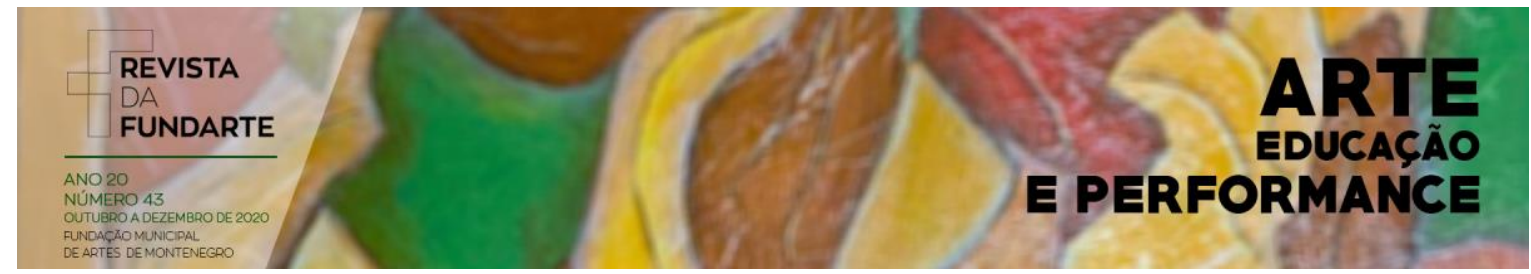

nas paredes das ruas. E, por fim, o Break Dance, elemento da dança no qual $B$-Boys e B-girls dançam ao som do DJ. Cada elemento é interligado e tem um significado para quem o pratica. Muito mais do que elementos vazios, são bases que estruturam a cultura e de como ela será mantida e passada adiante. Alves e Dias (2004) corroboram com a ideia de algo maior, algo que extrapola os elementos em si e configuram uma cultura.

A dança Break, portanto, assume uma função nobre que a conduz para as raízes da vida. Mais do que uma modalidade de dança, o Break é uma maneira de existir. Re-significando a existência através de sua própria expressão artística é uma atitude do corpo, a favor de sua própria valorização. (ALVES; DIAS, 2004, p. 6).

Por esse motivo, Ademir não se refere ao Hip Hop como um movimento, mas sim como uma cultura, uma vez que os praticantes e fundadores a tratam como tal. O desenho abaixo ilustra essa forma de ser e de pensar de seus praticantes.

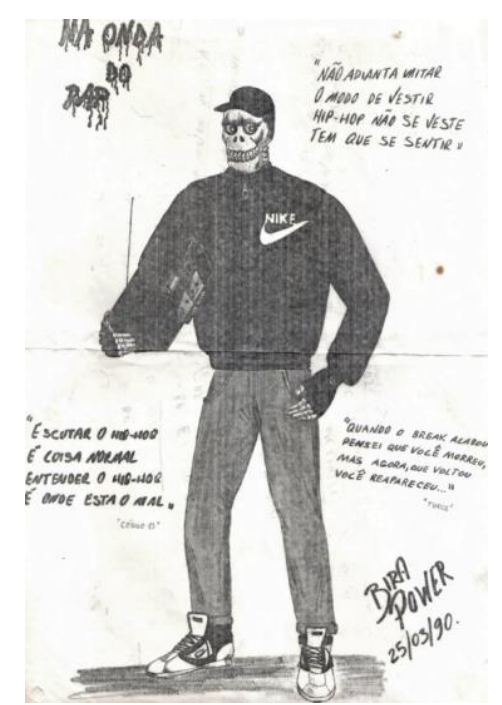

Figura 2: Desenho de Bira Power, 1990. Fonte: Acervo pessoal do entrevistado.

Ademir conta que a dança Breaking ou Break Dance é a única dança ligada à cultura Hip Hop e teve sua origem na cidade de Nova lorque (EUA). Entretanto, outras danças, como Locking e Popping (ambas nascidas na cidade de Los Angeles)

FERREIRA, Anne Caroline Paz; VALLE, Flavia Pilla. Memórias da dança: Ademir Porto Cavalheiro e os primórdios da cultura Hip Hop em Porto Alegre. Revista da FUNDARTE. Montenegro, p.01-20, ano 20, no 43, outubro/dezembro de 2020.

Disponível em: http://.seer.fundarte.rs.gov.br/index.php/revistadafundarte/index> 20 de dezembro de 2020. 


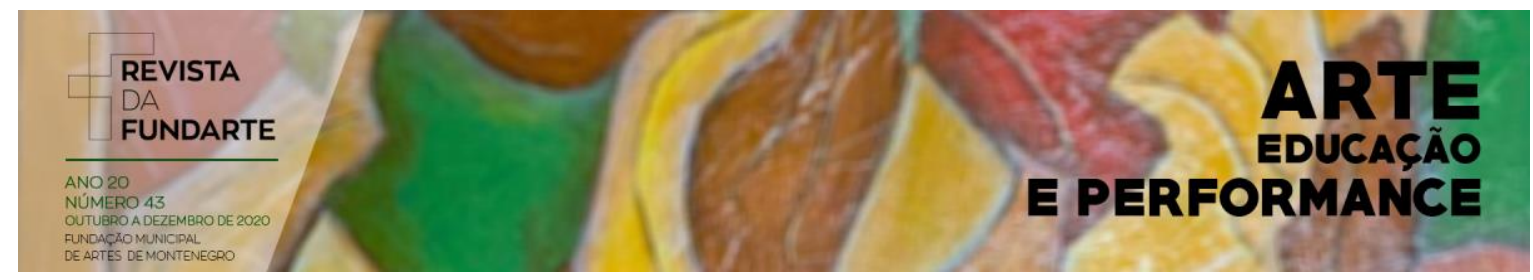

foram agregadas nas movimentações dos bailarinos locais à medida que esses viam referências em mídias televisivas.

Nos anos de 1980, em meio a um contexto violento no distrito Bronx, em Nova Iorque, Ademir assistiu a uma reportagem de televisão sobre os protestos nos Estados Unidos. Ele conta sobre a primeira vez que viu uma cypher (roda) de Breaking, que acontecia justamente como forma de protesto. Paralelo a esse movimento político, artistas como Michael Jackson e Lionel Richie alcançavam sucesso mundial e utilizariam as danças vindas do contexto de rua em seus videoclipes. Portanto, jovens como Ademir viriam a conhecer a dança de rua através de tais clipes. Pelo relato de Ademir, observa-se que Porto Alegre esteve atuante nos primórdios do Hip Hop no Brasil, mas que essa inserção ainda carece de registro, uma vez que o centro do País tem maior visibilidade e disseminação.

\begin{abstract}
No início da década de 80 do século XX ocorreu uma explosão da breakdance nos Estados Unidos da América, culminando numa série de filmes e aparições de dançarinos vinculados ao break nos meios de comunicação daquele país, mais precisamente a partir de 1982. No Brasil há aparições de filmes e clips de break já no ano de 1983 na cidade de São Paulo, onde os percussores do break no Brasil iniciaram suas atividades e deram continuidade no decorrer dos anos. (GUARATO, 2008, p. 62-63).
\end{abstract}

Apesar de o Breaking ter emergido como uma forma de dança de meninos negros norte-americanos, que utilizavam o movimento e o desafio para resolver brigas de gangues, ao invés de promovê-las, estes mesmos grupos ou crews começaram a ganhar proporções profissionais, à medida que saíam das ruas para os palcos com suas manobras acrobáticas, giros e movimentos no chão. Esses movimentos acrobáticos são melhorados por pantomima e movimentos em câmera lenta, que são acentuados pelo freeze - no qual uma pose é parada e congelada. A evolução do Breakdancing das ruas para os palcos, mudou a forma visual do gênero. À medida que se tornava uma performance profissional, se abandonavam algumas das características de uma forma crua e inovadora de rua, acelerando assim seu desenvolvimento (EMERY, 1988).

FERREIRA, Anne Caroline Paz; VALLE, Flavia Pilla. Memórias da dança: Ademir Porto Cavalheiro e os primórdios da cultura Hip Hop em Porto Alegre. Revista da FUNDARTE. Montenegro, p.01-20, ano 20, no 43, outubro/dezembro de 2020.

Disponível em: http://.seer.fundarte.rs.gov.br/index.php/revistadafundarte/index> 20 de dezembro de 2020. 


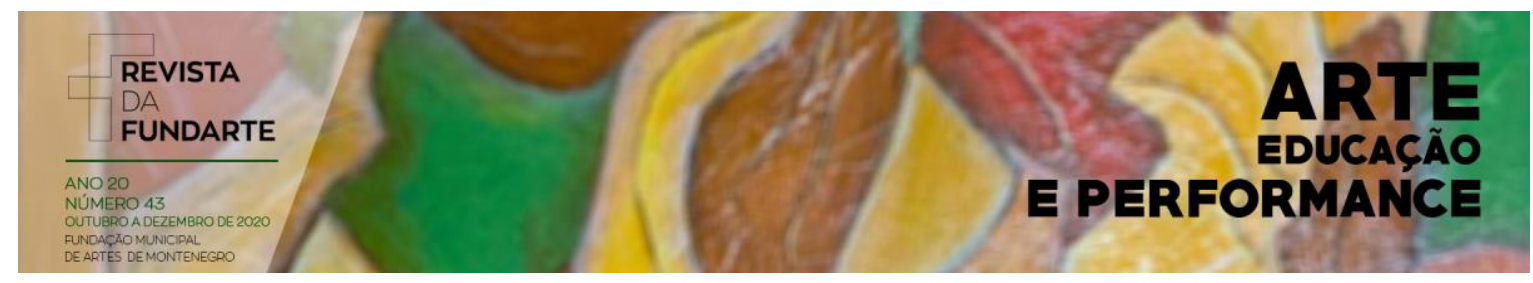

O Hip Hop emergiu dos guetos e era praticado e difundido pela comunidade negra. Se, num primeiro momento, foram danças marginalizadas e não legitimadas pela cultura dominante, através da mídia foi sendo disseminado e aceito no contexto mundial. Mas vale ter cautela quanto à sua aceitação.

É desse modo que o racismo passa da destruição das culturas e dos corpos com ela identificados, para a domesticação de culturas e de corpos. [...] o momento posterior da dinâmica do racismo é o enquadramento do grupo discriminado em uma versão de humanidade que possa ser controlada. Ao invés de destruir a cultura é mais inteligente determinar qual o seu valor e significado. (ALMEIDA, 2018, p. 56).

Alves e Dias (2004) destacam o grande alcance que essa dança teve no Brasil, extravasando o espaço das periferias e adentrando espaços legitimados como academias, centros culturais, áreas de lazer e de circulação central urbana.

\begin{abstract}
O estilo Hip-Hop de dançar passou a ser também um produto de mercado funcionando aos modos da clientela fitness. É preciso reconhecer que o Street Dance alcança um âmbito muito grande no espaço urbano. Jovens de toda a cidade, de todas as faixas etárias e de todas as classes sociais, experimentam a rebeldia da dança Break através do Street Dance. A via de acesso da cidade a esta arte é o ambiente particular das academias. Portanto, a cidade foi se apropriando da cultura Hip-Hop tornando-a um bem de consumo. (ALVES; DIAS, 2004, p. 6).
\end{abstract}

Os videoclipes e artistas internacionais foram essenciais na difusão do Hip Hop para o mundo, através da televisão. Embora não fosse levado à mídia com o título de Hip Hop, o jeito de vestir, falar e dançar explicitavam algumas características dessa cultura. Além disso, filmes de dança foram produzidos e lançados nessa época. Ademir destaca dois deles: Beat Street e Break Dance, ambos de 1984.

No primeiro filme citado, são abordadas as danças de Los Angeles: Locking e Popping. Já na segunda obra, vemos a dança de Nova lorque, o Breaking. Sobre o modo de aprender tais danças, Ademir nos diz que:

FERREIRA, Anne Caroline Paz; VALLE, Flavia Pilla. Memórias da dança: Ademir Porto Cavalheiro e os primórdios da cultura Hip Hop em Porto Alegre. Revista da FUNDARTE. Montenegro, p.01-20, ano 20, no 43, outubro/dezembro de 2020.

Disponível em: http://.seer.fundarte.rs.gov.br/index.php/revistadafundarte/index> 20 de dezembro de 2020. 


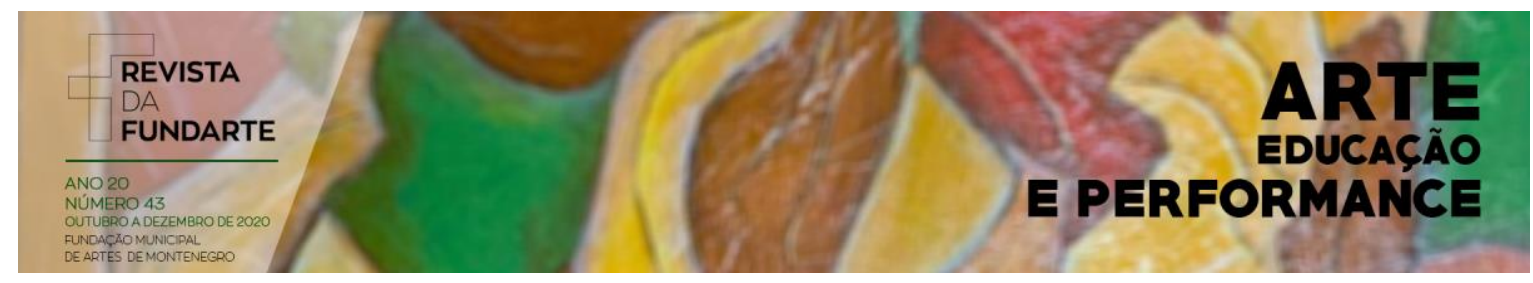

Tínhamos que ter a criatividade em cima daquilo que a gente via, de um determinado movimento que tu via no vídeo, tu tinha que criar em cima daquilo. Então a questão da criatividade e movimentos era baseado na intuição e na criação a partir de células de movimento. (CAVALHEIRO, 2018, entrevista).

Tal memória demonstra a íntima relação entre tecnologia e aprendizado, uma vez que não havia professores ou mestres, muito menos a remota ideia de aulas de tais técnicas em escolas de dança. Ele relata que assistiam a todos os horários dos filmes, e durante os intervalos das sessões, praticavam e ensinavam uns aos outros. A aprendizagem era autodidata, improvisada e criativa. Além da imitação ou cópia como podemos pensar em um primeiro momento, existia o componente da criação, pois nem tudo estava dado nas gravações que assistiam.

A relação com a tecnologia é corroborada na fala de Marco Rodrigues, o Bocão, que diz:

[...] a minha grande influência foi em 82 quando vi o Michael Jackson no Billy Jean... a gente conseguia ver o clipe... não tinha vídeo cassete, não tinha internet, não tinha tudo... a gente olhava uma vez, se quisesse ver de novo tinha que esperar tal hora para ver os passos. Comecei a imitar ele naquela época nas festas e reunião dançante e quando ia nos bailes do Jara. (RODRIGUES, 2016, 2'31').

Observa-se, então, a forte relação com a tecnologia, uma vez que aquele grupo local assimilava movimentos (ainda de que maneira despretensiosa e sem informações técnicas fundamentadas), a partir do que absorviam da cultura de massa.

\section{Cultura Hip Hop como Cultura Marginalizada}

Ademir relata que "até 1984 não se sabia que existia uma cultura e que ela tinha um nome, só víamos a dança e a música dela" (CAVALHEIRO, 2018, entrevista). Podemos perceber que o Hip Hop em Porto Alegre não era, até aquele

FERREIRA, Anne Caroline Paz; VALLE, Flavia Pilla. Memórias da dança: Ademir Porto Cavalheiro e os primórdios da cultura Hip Hop em Porto Alegre. Revista da FUNDARTE. Montenegro, p.01-20, ano 20, ํㅡ 43, outubro/dezembro de 2020.

Disponível em: http://.seer.fundarte.rs.gov.br/index.php/revistadafundarte/index> 20 de dezembro de 2020. 


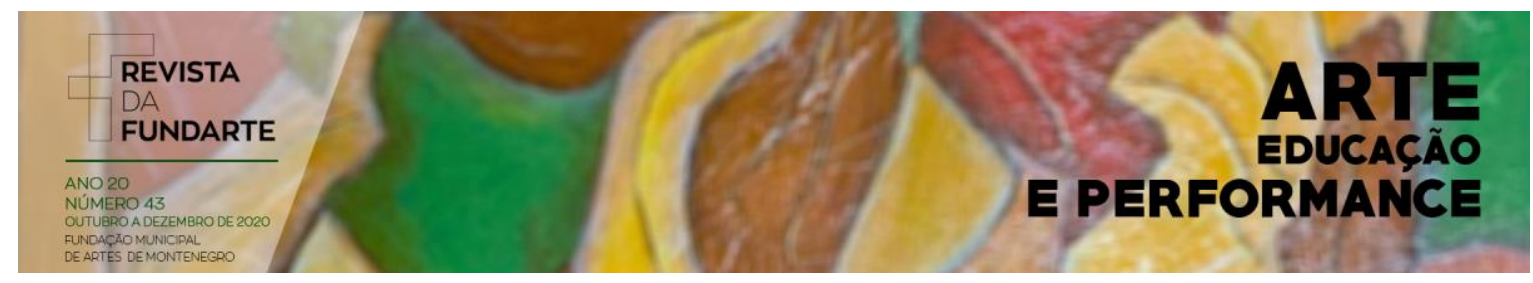

momento, apresentado como uma cultura com bases e preceitos filosóficos, mas sim utilizada como parte da cultura negra popular e que teve alcance mundial, através da cultura pop de massa.

Reckziegel e Stigger (2005, p. 65), ao pesquisar jovens integrantes do grupo Restinga Crew na periferia de Porto Alegre, já mais tarde, em 2003, elucidam que esses jovens, num primeiro momento, são atraídos pelo rap: “[...] para eles, as letras do rap 'passa alguma coisa', uma mensagem que os faz refletir sobre sua realidade, e contribuem para desencadear um processo de conscientização social e politica". Paralelo ao rap, os integrantes falam que iniciam sua prática pelo contato com os amigos ou grupos de sua própria comunidade. No início, o jovem é motivado pela satisfação que a dança lhe proporciona, e passa por um período de aprendizagem dos passos. Logo se dá conta da cultura que envolve a dança, através do próprio contato com os grupos de dança, "[...] não basta apenas saber dançar, mas é preciso saber o que é a dança, sua origem, sua história" (RECKZIEGEL; STIGGER, 2005, p. 67). É nessa fase que o jovem começa a tomar conhecimento sobre a cultura, quando os princípios ideológicos transmitidos por ela são incorporados pelos praticantes, e passam a reger o comportamento dos jovens dentro e fora do grupo. Após essa fase, há uma transformação na sua forma de pensar e agir, de modo que os jovens passam a se sentir parte dessa história e dessa cultura como um todo. Os autores defendem que "[...] ao optar pela dança, o grupo inicia um diálogo entre global e o local e deste diálogo, resulta a re-contextualização da cultura hip-hop e sua utilização para construir suas identidades, seus laços sociais e agir sobre seu meio [...]" (RECKZIEGEL; STIGGER, 2005, p. 71).

A cultura Hip Hop nasce de um contexto de reciclagem da cultura de massa, somada a um contexto de marginalização social. Ela nasce no Bronx, nos anos de 1970-1980, época na qual a população afro-americana e latina era segregada aos bairros mais afastados da cidade de Nova lorque. Essa população e essa nova cultura estavam longe do ideal de cultura propagado pelos padrões europeus.

FERREIRA, Anne Caroline Paz; VALLE, Flavia Pilla. Memórias da dança: Ademir Porto Cavalheiro e os primórdios da cultura Hip Hop em Porto Alegre. Revista da FUNDARTE. Montenegro, p.01-20, ano 20, n-43, outubro/dezembro de 2020.

Disponível em: http://.seer.fundarte.rs.gov.br/index.php/revistadafundarte/index> 20 de dezembro de 2020. 


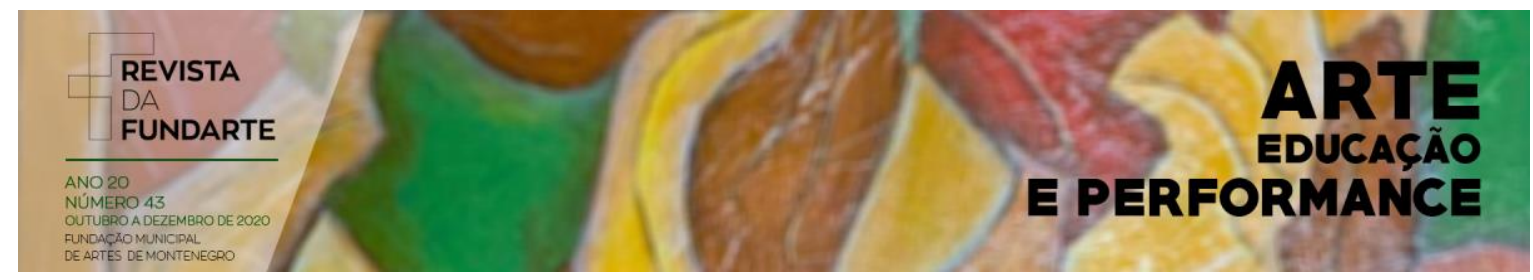

A expansão econômica mercantilista e a descoberta do novo mundo forjaram a base material a partir da qual a cultura renascentista iria refletir sobre a unidade e a multiplicidade da existência humana. Se antes deste período ser humano relacionava-se ao pertencimento de uma comunidade política ou religiosa, o contexto da expansão comercial burguesa e da cultura renascentista abriu as portas para a construção do moderno ideário filosófico que mais tarde transformaria o europeu no homem universal - o gênero aqui também é importante - e todos os povos e culturas não condizentes com os sistemas culturais europeus em variações menos evoluídas. (ALMEIDA, 2018, p. 19-20).

A trajetória de Ademir está ligada à sua identidade na condição de homem negro, oriundo de contexto periférico e participante de uma cultura de massa. Essa cultura, inicialmente, era não hegemônica, ou seja, estava fora dos ideais culturais europeus. Portanto, a cultura Hip Hop foge dos padrões clássicos e tradicionais da cultura dominante que vê o homem universal, dentro dos moldes e padrões europeizados, como a única definição de bom, belo e evoluído. A cultura Hip Hop vem carregada de uma estética negra e modos de fazer até então não convencionais: batidas cortadas, ritmos produzidos mecanicamente, e uma dança carregada de peso e agressividade.

As décadas de 1970-1980 em Nova lorque foram uma época de protestos, incêndios e reivindicações políticas, a respeito de moradia e acesso. A violência era grande. Haviam gangues e ataques em zonas conflituosas. No meio disso tudo, emerge um estilo não apenas de cantar, dançar e fazer música, mas também de olhar para suas próprias questões como comunidade, a partir da arte e do lugar que ela proporcionava, principalmente, para a juventude negra da época.

As experiências desses grupos localizados socialmente de forma hierarquizada e não humanizada faz com que as produções intelectuais, saberes e vozes sejam tratadas de modo igualmente subalternizado, além das condições sociais os manterem num lugar silenciado estruturalmente. Isso, de forma alguma significa que esses grupos não criam ferramentas para enfrentar esses silêncios institucionais, ao contrário, existem várias formas de organização políticas, culturais e intelectuais. (RIBEIRO, 2017, p. $63)$.

FERREIRA, Anne Caroline Paz; VALLE, Flavia Pilla. Memórias da dança: Ademir Porto Cavalheiro e os primórdios da cultura Hip Hop em Porto Alegre. Revista da FUNDARTE. Montenegro, p.01-20, ano 20, ํㅡ 43, outubro/dezembro de 2020.

Disponível em: http://.seer.fundarte.rs.gov.br/index.php/revistadafundarte/index> 20 de dezembro de 2020. 


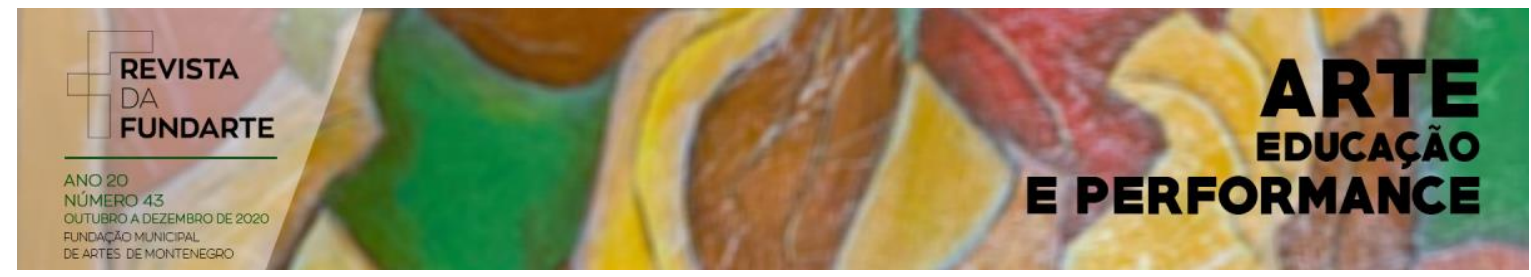

O Hip Hop nasce da falta de recursos. Ao não se ter acesso ao lazer, criou-se expressões artísticas próprias. Se não há acesso às ferramentas para a criação artística, os DJs entram em ação e remixam trechos de músicas já existentes, criando assim, um novo ritmo e batida. A necessidade de uma expressão que represente a comunidade dá vida ao Hip Hop e às manifestações culturais contidas nela. A necessidade de reivindicação cria a necessidade de os corpos se engajarem não apenas politicamente, mas antes de tudo com suas próprias gírias, modo de falar, vestir e de se comportar.

\section{Hip Hop em Porto Alegre}

Segundo Ademir, o Hip Hop na cidade iniciou como uma forma de lazer. A introdução dessa cultura se dá ao acaso nos bailes blacks de soul e funk da comunidade negra da cidade, organizados nas periferias. Ou seja, o Hip Hop era praticado como elemento cultural, ainda que sem se chamar Hip Hop. A comunidade negra e afastada dos centros de lazer cria sua própria maneira de expressão e socialização que, no caso do Hip Hop, ocorreu através das expressões artísticas, da festa, do que é divertido e, principalmente, do corpo.

Se, antes, as manifestações artísticas de dança no contexto urbano aconteciam, principalmente, em rodas nos bailes blacks, nas quais os praticantes balançavam seus corpos ao som de funk e soul, com as manipulações do DJ - que selecionava trechos de músicas já produzidas e as repetia em loop, criando batidas novas -, a maneira de se movimentar também foi sendo alterada conforme essa nova forma musical foi se espalhando entre a juventude, nos cenários urbanos das metrópoles.

Os movimentos corporais da dança breaking se adaptaram as características dessa nova trilha sonora a medida que a linearidade rítmica convencional começou a dar lugar a construções musicais baseadas na

FERREIRA, Anne Caroline Paz; VALLE, Flavia Pilla. Memórias da dança: Ademir Porto Cavalheiro e os primórdios da cultura Hip Hop em Porto Alegre. Revista da FUNDARTE. Montenegro, p.01-20, ano 20, n -43 , outubro/dezembro de 2020.

Disponível em: http://.seer.fundarte.rs.gov.br/index.php/revistadafundarte/index> 20 de dezembro de 2020. 


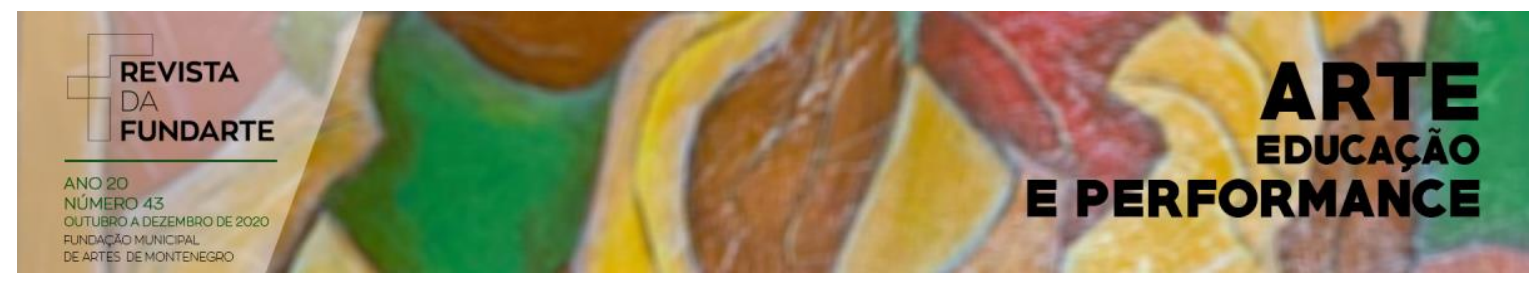

repetição de fraseados e em arranjos musicais mais ousados - 'quebrados'. (TRIUNFO apud YOSHINAGA, 2014, p. 168).

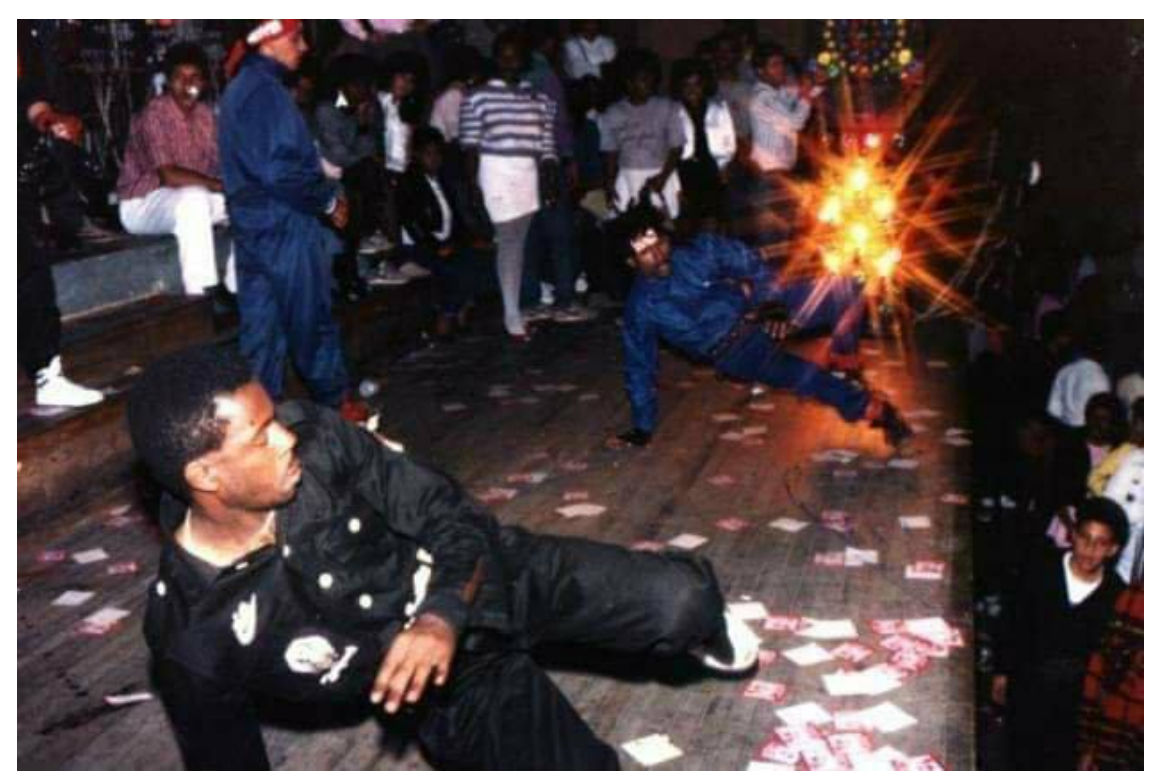

Figura 3: Ademir dançando nos anos 1980. Fonte: Acervo pessoal do entrevistado.

Ademir destaca que a dança se fortalece quando seu amigo Gedair (sobrenome desconhecido) reúne bailarinos que, além de Soul e Funk, dançavam Popping e alguns passos de Breaking em 1983. Nesse mesmo ano acontece a Primeira Mostra de Breaking de Porto Alegre (POA), na qual Ademir e Gedair se apresentam junto com outros integrantes - Cadinho, Paulo, Mestre Fu e Jair. Na sequência, criam o primeiro grupo de Breaking da cidade, chamado Break Stones. Além do Break Stones, Ademir participou de grupos como Deryl Devils, Hackers Crew e Spider Beat.

FERREIRA, Anne Caroline Paz; VALLE, Flavia Pilla. Memórias da dança: Ademir Porto Cavalheiro e os primórdios da cultura Hip Hop em Porto Alegre. Revista da FUNDARTE. Montenegro, p.01-20, ano 20, ํㅡ 43, outubro/dezembro de 2020.

Disponível em: http://.seer.fundarte.rs.gov.br/index.php/revistadafundarte/index> 20 de dezembro de 2020. 

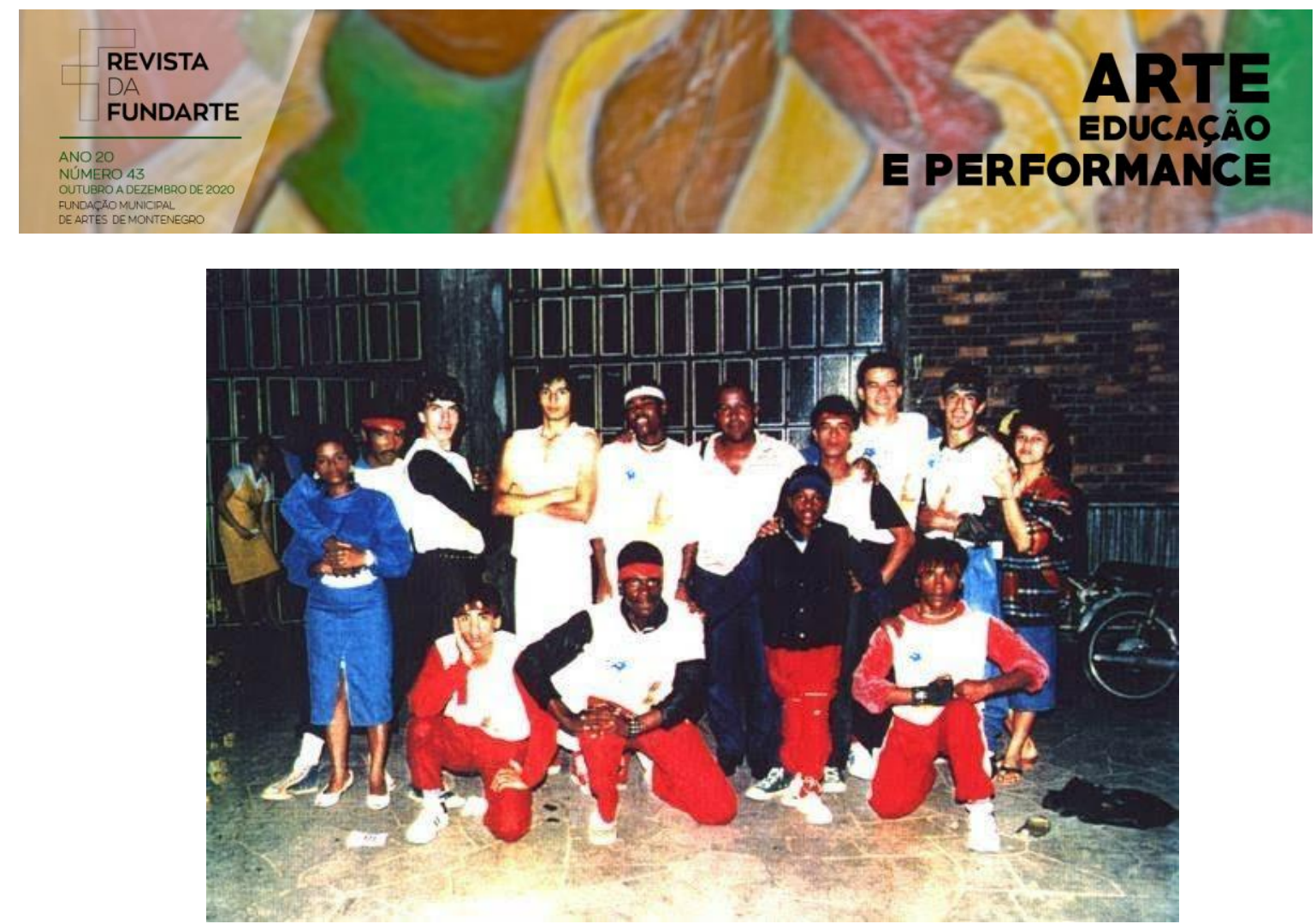

Figura 4: Hackers Crew e amigos em 1986. Fonte: Acervo pessoal do entrevistado.

Ademir relata alguns eventos que abrigavam a comunidade participante da cultura naquela época, como o Canecão de Ouro, Furacão 2000 - mega cypher, Jara e Black Porto. O Canecão de Ouro abrigou grandes batalhas de Locking, Popping e Breaking e foi onde se formou posteriormente a Hackers Crew. Na Furacão 2000, o grupo Dear Devils ganha a primeira premiação de grupo gaúcho. Marco Rodrigues fala o seguinte sobre o Grupo Jara: "[...] comecei a imitar ele [Michael Jackson] naquela época, nas festas e reuniões dançantes e quando ia nos bailes do Jara. O Jara era um DJ que movimentava muito nos anos 80 . junto com tantos outros que tinha na época" (RODRIGUES, 2016, 2’31”). Sobre o Jara, Ademir guarda um flyer de divulgação da época.

FERREIRA, Anne Caroline Paz; VALLE, Flavia Pilla. Memórias da dança: Ademir Porto Cavalheiro e os primórdios da cultura Hip Hop em Porto Alegre. Revista da FUNDARTE. Montenegro, p.01-20, ano 20, ํㅡ 43, outubro/dezembro de 2020.

Disponível em: http://.seer.fundarte.rs.gov.br/index.php/revistadafundarte/index> 20 de dezembro de 2020. 


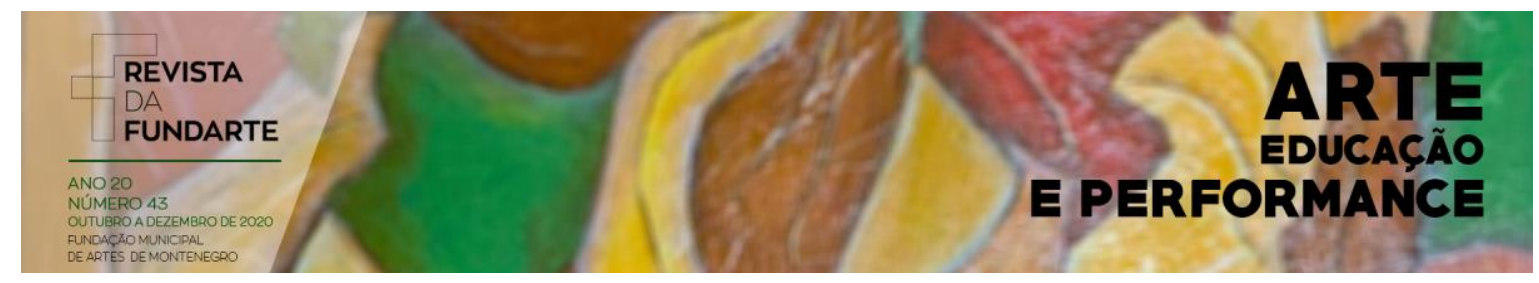

\title{
Grupo Jara Musi-Som
}

\author{
DIA 20 DE OUTUBRO \\ GINASIO DO PROTASIO \\ Atrações: \\ BIRA POWER, MARIO PESÃOO \\ J. CLIP SOM, SPEDER \\ As atraçōes que faltaram no BLACK PORTO \\ FIQUE VIVO: Vem ai o TROFEU BLACK PORTO 90
}

Figura 5: Flyer de divulgação do evento "Grupo Jara Musi-Som". Sem ano. Fonte: Acervo pessoal do entrevistado.

Contrariando o que o senso comum nos diria sobre remuneração de artistas, especialmente de dança de rua, Ademir relata que nos anos 1980 seu grupo se sustentava completamente da dança, realizando uma média de cinco a seis apresentações mensais remuneradas: "[...] nos mantínhamos completamente da dança. Abrimos alguns espaços pra Dança de Rua: desfiles de moda, lojas, escolas de dança, clubs gays, boates. Apenas não aceitávamos direção dos contratantes, fazíamos do nosso jeito" (CAVALHEIRO, 2018, entrevista). A respeito das apresentações, ele diz que não aceitavam a direção alheia, pois não queriam interferência em suas criações artísticas. Os grupos circulavam pelo circuito de bailes black na cidade e em cidades no interior do estado do Rio Grande do Sul. Ademir relembra que tudo acontecia no boca a boca, de maneira informal, mas sempre se cumpriam os compromissos quanto aos valores acordados. E reforça que “[...] não tínhamos uma preocupação com grande público. Nosso foco era auto superação técnica e respeito, a partir disso. Qualificar e expandir aquela dança. Era um tesouro a ser preservado" (CAVALHEIRO, 2018, entrevista).

Há depoimentos que dão pistas sobre a relação do Hip Hop com as academias de ginástica, também como um meio de sustento. Mike Junior, da Alpha

FERREIRA, Anne Caroline Paz; VALLE, Flavia Pilla. Memórias da dança: Ademir Porto Cavalheiro e os primórdios da cultura Hip Hop em Porto Alegre. Revista da FUNDARTE. Montenegro, p.01-20, ano 20, no 43, outubro/dezembro de 2020.

Disponível em: http://.seer.fundarte.rs.gov.br/index.php/revistadafundarte/index> 20 de dezembro de 2020. 


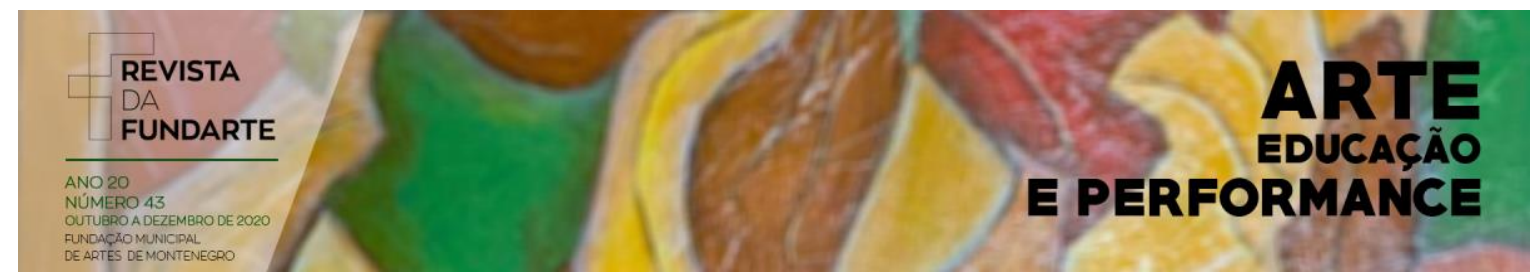

Company, menciona "suar a camiseta" (JUNIOR, 2016, 1'28"), trazendo, provavelmente, uma relação com a ginástica aeróbica que estourou nos anos 1990 em Porto Alegre. Sobre esse aspecto, Julinho Dancehall fala sobre Marco Rodrigues, o Bocão: "[...] conheci o Marco em 1994, 1995. Eu conheci ele dando aula em uma academia, na rede parcão, dando aula. Foi o primeiro cara que eu conheci que dava liga" (DANCEHALL, 2016, 1'45").

O estilo Hip-Hop de dançar passou a ser também um produto de mercado funcionando aos modos da clientela fitness. É preciso reconhecer que o Street Dance alcança um âmbito muito grande no espaço urbano. Jovens de toda a cidade, de todas as faixas etárias e de todas as classes sociais, experimentam a rebeldia da dança Break através do Street Dance. A via de acesso da cidade a esta arte é o ambiente particular das academias. Portanto, a cidade foi se apropriando da cultura Hip-Hop tornando-a um bem de consumo. (ALVES; DIAS, 2004, p. 6).

\section{Representatividade Negra no Hip Hop}

O Hip Hop nasce no gueto em um contexto violento, toma as ruas como forma de expressão e busca, por maneiras próprias, viver a realidade de um grupo específico de pessoas. Tem sua difusão por meio de artistas negros norteamericanos de grande influência, e expande-se aos bairros negros em outro continente. Jovens negros incorporam a maneira Hip Hop de ser, falar e vestir.

Alex Sandro Gomes, da Enthus Cia de Dança, sobre o início do Hip Hop em Porto Alegre, menciona que "[...] entrar numa escola de brancos, ricos, para dar aula de Hip Hop... o neguinho tinha que ser muito gente fina, para entrar lá com isso tá?!" (GOMES, 2016, 4'48")

Apesar de a cultura Hip Hop também ser utilizada como um modo de representar partes da cultura negra e ressignificar seu valor na contemporaneidade, assim como produzir autoestima em indivíduos negros, precisamos estar atentos aos limites dessa representatividade:

FERREIRA, Anne Caroline Paz; VALLE, Flavia Pilla. Memórias da dança: Ademir Porto Cavalheiro e os primórdios da cultura Hip Hop em Porto Alegre. Revista da FUNDARTE. Montenegro, p.01-20, ano 20, n 43, outubro/dezembro de 2020.

Disponível em: http://.seer.fundarte.rs.gov.br/index.php/revistadafundarte/index> 20 de dezembro de 2020. 


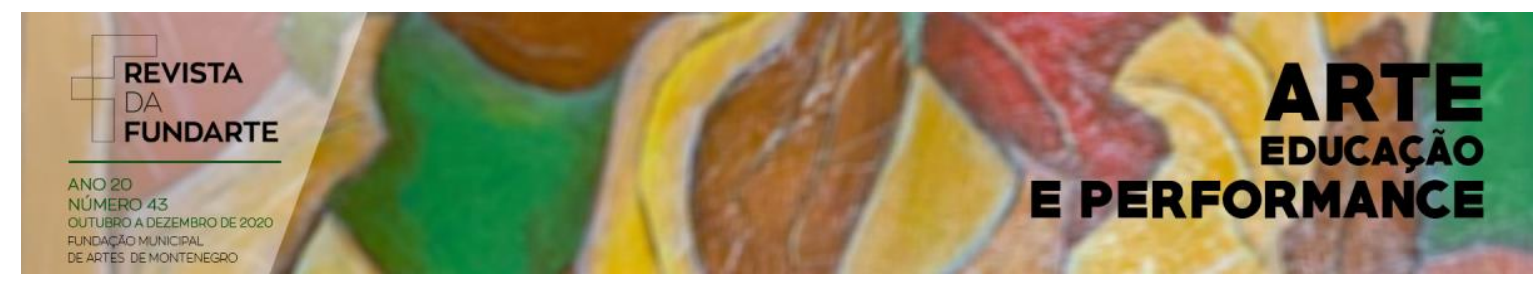

[...] o racismo não se resume a um problema de representatividade, mas é uma questão de poder real. $O$ fato de uma pessoa negra estar na liderança, não significa que esteja no poder e muito menos que a população negra esteja no poder. (ALMEIDA, 2018, p. 85).

O surgimento do Hip Hop, tanto nos Estados Unidos quanto em Porto Alegre, teve sua origem, difusão e inserção através dos bailes e bairros de comunidade negra. Não é apenas uma dança ou música, é então um modo de ser e estar no mundo, um lugar de pertencimento. Tal qual acontecia no Rio de Janeiro

[...] seus bailes assumiam uma forma didática, introduzindo a cultura negra através de figuras já conhecidas dos dançarinos, isto é, celebridades da música e dos esportes. As danças do 'Soul Grand Prix', na verdade, usavam mídia mista - slides, filmes, fotos, pôsteres etc. - para inculcar o estilo 'Black is beautiful' da época. (YÚDICE, 2004, p. 176).

Nesse sentido, quando questionado sobre a representatividade negra no Hip Hop, Ademir nos diz: "Aquilo tudo era uma folha da cultura negra. A cultura deveria acontecer como uma forma de resistência. A questão da negritude estava ligada à própria arte" (CAVALHEIRO, 2018, entrevista).

\section{Para Finalizar}

Ademir demonstra, a partir de seus relatos, que a cultura Hip Hop e as danças urbanas tiveram um impacto direto na juventude porto-alegrense, sobretudo periférica, nos anos 1980. Tal manifestação cultural pode ser observada não só como um fenômeno passageiro, mas como uma cultura que permanece e se recicla com o passar do tempo, à medida que vai se espalhando e sendo assimilada pelas juventudes.

Ademir traz dados importantes da relação entre dança, tecnologia e aprendizagem, algo que já acontecia naquela época e que demonstra o caráter criativo, e evidencia algumas características das danças urbanas no geral, como o improviso ou Freestyle, que são partes constituintes da cultura das cyphers.

FERREIRA, Anne Caroline Paz; VALLE, Flavia Pilla. Memórias da dança: Ademir Porto Cavalheiro e os primórdios da cultura Hip Hop em Porto Alegre. Revista da FUNDARTE. Montenegro, p.01-20, ano 20, n 43, outubro/dezembro de 2020.

Disponível em: http://.seer.fundarte.rs.gov.br/index.php/revistadafundarte/index> 20 de dezembro de 2020. 


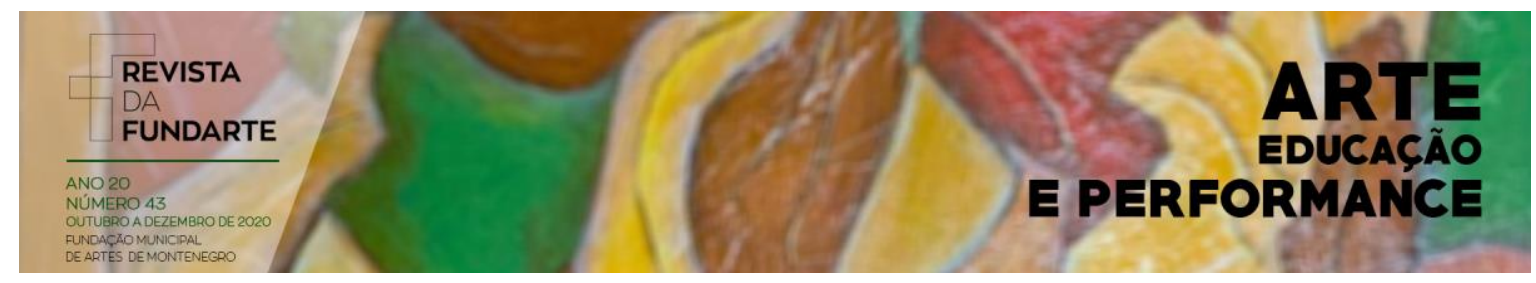

Ainda em relação à tecnologia, vemos que a cultura Hip Hop se torna um produto da cultura de massa, uma vez que aparece com força na televisão e em clipes de artistas pop. Entretanto, ela não deve ser vista como um subproduto ou mero fenômeno passageiro, como nos relatou Ademir. Observamos a nítida relação com questões de caráter político e reivindicação de direito de minorias, ainda que com uma roupagem pop.

A partir dessas constatações, diversas outras questões podem ser levantadas ou aprofundadas para a continuidade desta pesquisa. Dentre elas: como se dá a relação entre esta cultura de massa e movimentos sociais? Quanto ao fato de existir apenas uma integrante mulher no grupo Hackers Crew e de não haver outras citações e referências a figuras femininas no cenário da cultura e da dança naquela época - onde estavam essas mulheres?

Em relação à representatividade negra no Hip Hop mais investigações precisam ser feitas, uma vez que é um tema complexo que perpassa outros temas, como questões sociais, de classe e gênero. Contudo, foram obtidas respostas afirmativas que apontam para um sentimento de pertencimento e valorização de uma identidade negra, a partir do que se pratica na cultura Hip Hop: o modo de pensar, agir, falar e se vestir. O Hip Hop, portanto, poderia ser visto como um lugar de visibilidade e importância social, negado em outros espaços formais e intelectualizados. Ele tem seus saberes ligados à própria prática, saberes que são então cultivados no fazer.

O Hip Hop é uma cultura que se internacionalizou e fomentou uma identidade negra forte em diversos locais, inclusive em Porto Alegre. Hoje, ela se institucionalizou e está dentro das escolas e academias, não só como técnica e sim como uma técnica que emerge de uma cultura. Discutir e pesquisar o Hip Hop em Porto Alegre é importante para gerar os registros históricos locais, e a universidade de arte e dança tem um papel relevante nessa questão, visto que no Brasil é um dos principais locais de pesquisa. Esses registros, por sua vez, contribuem para os primórdios da cultura Hip Hop em Porto Alegre. Revista da FUNDARTE. Montenegro, p.01-20, ano 20, no 43, outubro/dezembro de 2020.

Disponível em: http://.seer.fundarte.rs.gov.br/index.php/revistadafundarte/index> 20 de dezembro de 2020. 


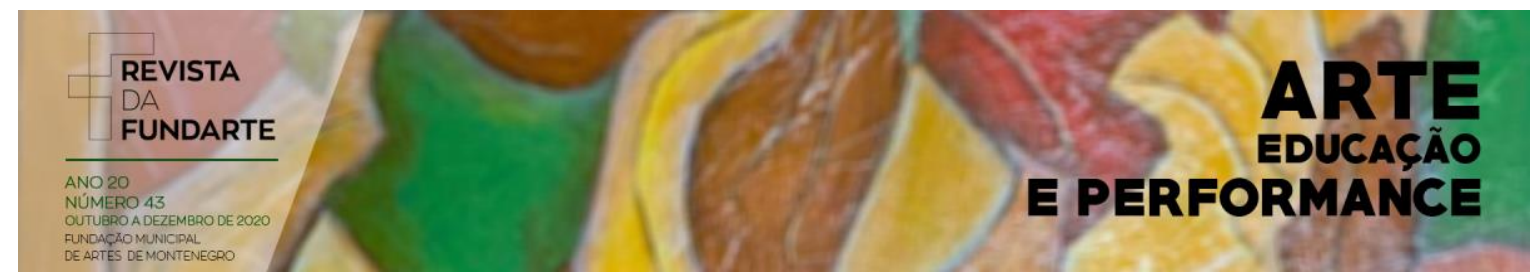

fortalecer a identidade negra e fomentar uma educação que valorize as relações étnico-raciais.

\section{Referências:}

ALMEIDA, Silvio. O que é racismo estrutural. Belo Horizonte: Letramento, 2018.

ALVES, Flavio Soares; DIAS, Romualdo. A dança Break: corpos e sentidos em movimento no Hip-Hop. Motriz, Rio Claro, v. 10, n. 1, p. 01-07, jan./abr. 2004. Disponível em: <http://www.periodicos.rc.biblioteca.unesp.br/index.php/motriz/article/view/937>. Acesso em: 22 mar. 2020.

BURKE, Peter. A Escrita da história: novas perspectivas. São Paulo: Editora da Universidade Estadual Paulista, 1992.

CAVALHEIRO, Ademir P. Entrevista. Entrevistadora Anne Caroline Paz Ferreira. Porto Alegre: 15 ago. 2018. 45 min.

DANCEHALL, Julinho. $1^{\circ}$ Painel de Danças Urbanas (registro de vídeo). In: GRUPO MY HOUSE. Direção de Marco Rodrigues. Porto Alegre: Sala Rony Leal/Usina do Gasômetro, 22/2/2016. 12 min. Disponível em: <https://youtu.be/80SVKBNX1Y8>. Acesso em: 10 ago. 2019.

EMERY, Lynne Fauley. Black Dance: from 1619 to today. 2. ed. Hightstown: Princeton, 1988.

GOMES, Alex Sandro. $1^{\circ}$ Painel de Danças Urbanas (registro de vídeo). In: GRUPO MY HOUSE. Direção de Marco Rodrigues. Porto Alegre: Sala Rony Leal/Usina do Gasômetro, 22/2/2016. 12 min. Disponível em: <https://youtu.be/80SVKBNX1Y8>. Acesso em: 10 ago. 2019.

GUARATO, Rafael. Dança de rua: corpo para além do movimento (Uberlândia 19702007). Uberlândia: EDUFU, 2008.

JUNIOR, Mike. $1^{\circ}$ Painel de Danças Urbanas (registro de vídeo). In: GRUPO MY HOUSE. Direção de Marco Rodrigues. Porto Alegre: Sala Rony Leal/Usina do Gasômetro, 22/2/2016. 12 min. Disponível em: <https://youtu.be/80SVKBNX1Y8>. Acesso em 10 ago. 2019.

FERREIRA, Anne Caroline Paz; VALLE, Flavia Pilla. Memórias da dança: Ademir Porto Cavalheiro e os primórdios da cultura Hip Hop em Porto Alegre. Revista da FUNDARTE. Montenegro, p.01-20, ano 20, n 43, outubro/dezembro de 2020.

Disponível em: http://.seer.fundarte.rs.gov.br/index.php/revistadafundarte/index> 20 de dezembro de 2020. 


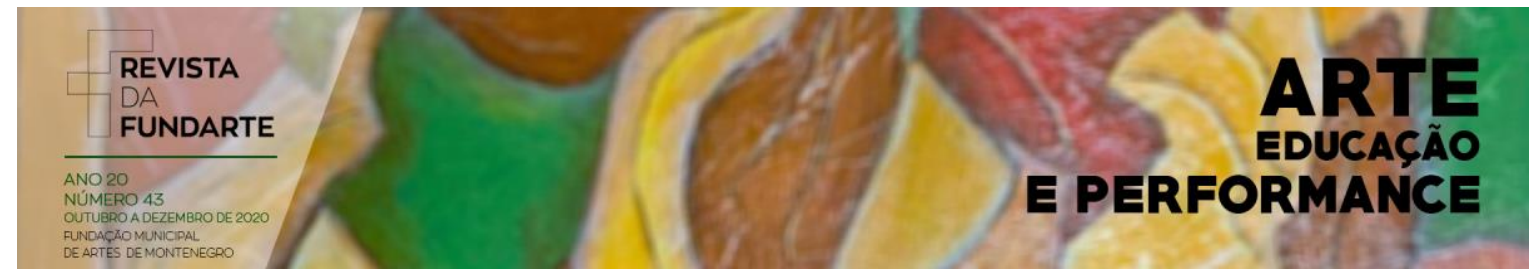

RECKZIEGEL, Ana Cecília de Carvalho; STIGGER, Marco Paulo. Dança de rua: opção pela dignidade e compromisso social. Movimento, Porto Alegre, v. 11, n. 2, p. 59-73, maio/ago. 2005.

Disponível em: <https://www.lume.ufrgs.br/handle/10183/20024>. Acesso em: 22 mar. 2020.

RIBEIRO, Ribeiro. O que é lugar de fala?. Belo Horizonte: Letramento, 2017.

RODRIGUES, Marco. $1^{\circ}$ Painel de Danças Urbanas (registro de vídeo). In: GRUPO MY HOUSE. Direção de Marco Rodrigues. Porto Alegre: Sala Rony Leal/Usina do Gasômetro, 22/2/2016. 12 min. Disponível em: <https://youtu.be/80SVKBNX1Y8>. Acesso em: 10 ago. 2019.

YOSHINAGA, Gilberto. Nelson Triunfo: do sertão ao Hip-Hop. São Paulo: Shuriken Produções/LiteraRUA, 2014.

YÚDICE, George. A convivência da cultura: uso da cultura na era global. Belo Horizonte: UFMG, 2004.

FERREIRA, Anne Caroline Paz; VALLE, Flavia Pilla. Memórias da dança: Ademir Porto Cavalheiro e os primórdios da cultura Hip Hop em Porto Alegre. Revista da FUNDARTE. Montenegro, p.01-20, ano 20, no 43, outubro/dezembro de 2020.

Disponível em: http://.seer.fundarte.rs.gov.br/index.php/revistadafundarte/index> 20 de dezembro de 2020 . 